\title{
La agricultura de los Andes venezolanos: De la intensificación a la crisis, 1960-2019
}

DAVID LEROY

\author{
PALABRAS CLAVE: agricultura, Andes venezolanos, intensificación, \\ crisis.
}

\section{CÓDIGOS JEL: N56, O13, Q1, Q18.}

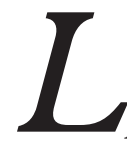

os Andes venezolanos eran una de las regiones más pobres del país durante las décadas de 1950-1960. Esta región se encontraba afectada por la explotación petrolera y la urbanización acelerada. Sin embargo, con la introducción de la horticultura de riego en esa época se cambiaron radicalmente los sistemas de producción andinos con el desarrollo de cultivos de alto valor comercial, por lo que durante varias décadas los Andes venezolanos fueron una fuente importante de enriquecimiento y un nuevo polo de crecimiento para el país. No obstante, a partir de la década de 1990 con la intensificación de las actividades de horticultura comenzaron a manifestarse problemas, tanto en términos socioeconómicos como medioambientales. Este proceso se acentuó a partir de 2013 con la crisis económica, política y social que sigue afectando a Venezuela. Hoy en día los agricultores andinos del país se enfrentan a varios obstáculos (escasez de combustible, dolarización de la economía, pérdida de poder adquisitivo de los consumidores, altos precios de los insumos) que hacen que la inversión agrícola sea particularmente arriesgada. En un contexto de escasez de alimentos e hiperinflación, la agricultura de subsistencia está regresando a los Andes venezolanos, lo que permite a los agricultores producir suficientes alimentos para ellos y sus familias. 


\section{Agriculture in the Venezuelan Andes: \\ From intensification to crisis, 1960-2019}

\section{KEYWORDS: agriculture, Venezuelan Andes, intensification, crisis.}

\section{JEL CODES: N56, O13, Q1, Q18.}

heVenezuelan Andes constituted one of the poorest regions of the country dur-
ing the 1950s-1960s. This region was affected by oil exploitation and rapid
urbanization. However, with the introduction of irrigated horticulture at that time, the Andean production systems were radically changed with the development of crops of high commercial value. For several decades, the Venezuelan Andes were an important source of enrichment and a new growth pole for the country. From the 1990s, however, with the intensification of horticultural activities, problems began to manifest themselves in both socio-economic and environmental terms. This process was accentuated from 2013 with the economic, political and social crisis that continues to affect Venezuela. Today the country's Andean farmers face several obstacles (fuel shortages, dollarization of the economy, loss of consumer purchasing power, high input prices) that make agricultural investment particularly risky. In a context of food shortages and hyperinflation, subsistence farming is returning to the Venezuelan Andes, allowing farmers to produce enough food for themselves and their families.

Recepción: 2019-12-11 - Revisión: 2020-07-08 - Aceptación: 2020-07-09

David Leroy [orcid.org/0000-0002-7170-0210] es investigador posdoctoral en el Centro de Investigaciones en Geografía Ambiental (CIGA) de la Universidad Nacional Autónoma de México (UNAM). Dirección para correspondencia: Centro de Investigaciones en Geografía Ambiental. UNAM, campus Morelia, Antigua Carretera a Pátzcuaro No. 8701, Col. Ex-Hacienda de San fosé de la Huerta. C.P. 58190. Morelia, Michoacán, México.C.edleroy@ciga.unam.mx; david.univ.leroy@gmail.com 


\section{INTRODUCCIÓN}

En la década de 1950, los Andes venezolanos eran una de las regiones más pobres del país. $\mathrm{Al}$ estar demasiado alejados de la capital, sus pobladores recibieron pocos réditos por el crecimiento económico ligado al descubrimiento y explotación del petróleo. Por el contrario, el enriquecimiento vinculado a los hidrocarburos había llevado a la marginación de su único recurso comercial tradicional, el café, con el cual muchas personas habían hecho fortuna a finales del siglo XIX. Este declive económico hizo de la región andina venezolana un polo de emigración particularmente intenso (Tulet, 2002).

Pero a partir de los años setenta del siglo xx, esta dinámica se vio invertida por el desarrollo de una nueva actividad agrícola: la horticultura intensiva. De hecho, en aquella época, la demanda urbana de hortaliza tuvo un boom en Venezuela, siendo las zonas de montaña las únicas en condición de satisfacer la nueva y gran demanda debido a las condiciones ecológicas específicas. La principal herramienta de transformación fue el establecimiento de unos pequeños sistemas de riego colectivo que estuvieron financiados por dos programas estatales de desarrollo.

Los Andes venezolanos durante muchos años fueron una fuente importante de enriquecimiento y un nuevo polo de crecimiento para el país. Sin embargo, a partir de los años 1990, la intensificación de las actividades de horticultura comenzó a mostrar sus falencias en términos socioeconómicos y ambientales (Velázquez, 2001a; Angéliaume-Descamps \& Oballos, 2009). Además, desde 2013, Venezuela se enfrenta a una crisis económica sin precedentes, que tiene consecuencias considerables para la agricultura y, por ende, para la seguridad alimentaria de la población.

Por lo tanto, es necesario considerar los factores económicos, sociales y políticos que llevaron a la agricultura andina venezolana a esta situación de crisis. La exposición de esta obra está guiada por una serie de preguntas: ¿Cuáles fueron los elementos que permitieron el desarrollo de la horticultura andina en los Andes venezolanos? ¿Cómo una economía basada en el petróleo, como la venezolana, debilitó el sector agrícola? ¿Cómo se ve afectada la agricultura andina venezolana por la reciente crisis? ¿Las comunidades rurales pueden adaptarse a esta crisis?

En primer lugar, presentaremos nuestra área de estudio y la metodología de esta investigación. Después, analizaremos los elementos que impulsaron el desarrollo de la horticultura de regadío en los Andes venezolanos. Para finalizar, nos centraremos en los acontecimientos socioeconómicos más recientes y, en particular, en las consecuencias de la crisis venezolana en la agricultura andina. 


\section{2. ÁREA DE ESTUDIO Y METODOLOGÍA}

El valle del Alto Chama está ubicado en el municipio Rangel (capital Mucuchíes) del estado de Mérida, a una altitud entre $2.700 \mathrm{~m} \mathrm{s.} \mathrm{n.} \mathrm{m.} \mathrm{y} 4.640 \mathrm{~m} \mathrm{~s} . \mathrm{n}$. m. El área delimitada para el estudio ocupa dos comunidades de este valle agrícola. La comunidad de Misintá, de 517 habitantes, está ubicada en la vertiente sur de la sierra de La Culata. La comunidad de Mixteque, con 395 habitantes, está ubicada en su totalidad en la vertiente norte de la sierra Nevada.

\section{FIGURA 1}

\section{Área de estudio}

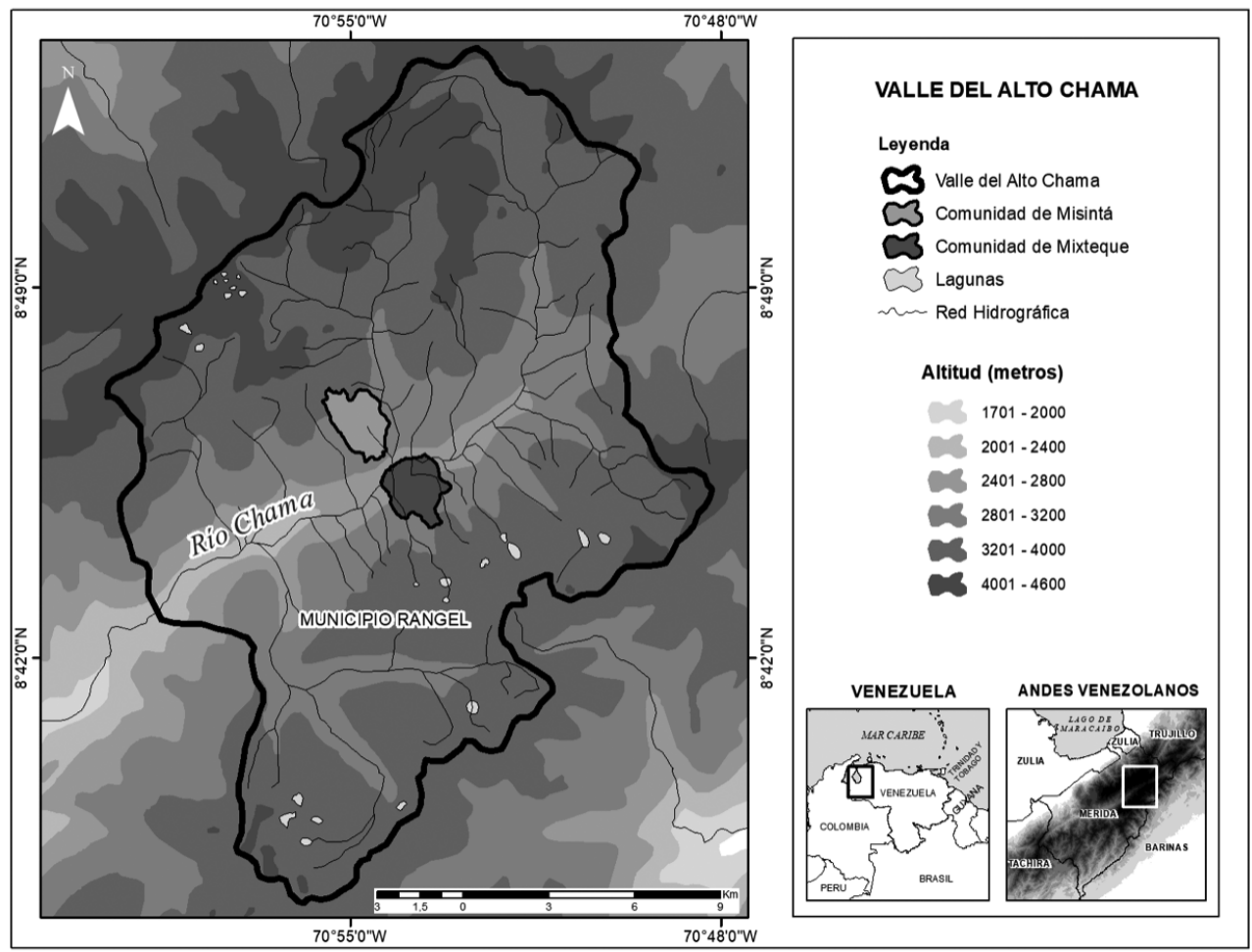

Fuente: realizado por Efraín Porto Tapiquén y David Leroy.

Nuestra área de estudio está ubicada en el páramo, un ecosistema de altura (2.700$4.500 \mathrm{~m} \mathrm{s.} \mathrm{n.} \mathrm{m.)} \mathrm{específico} \mathrm{de} \mathrm{los} \mathrm{Andes} \mathrm{del} \mathrm{norte} \mathrm{(Colombia,} \mathrm{Ecuador,} \mathrm{Venezuela} \mathrm{y} \mathrm{el}$ norte de Perú). El páramo es conocido por su biodiversidad y sus excepcionales paisajes, pero también por su rol estratégico en la retención y regulación de los recursos hídricos (Hofstede, Segarra \& Mena, 2003; Monasterio \& Molinillo, 2003). Éste alberga 
numerosas lagunas y humedales que constituyen reservorios naturales de agua de vital importancia para las poblaciones andinas de Venezuela (Llambí \& Rada, 2019). Los parques nacionales de Sierra Nevada (1952) y Sierra de La Culata (1989) fueron creados para proteger estas áreas frágiles.

El clima de esta zona es tropical montañoso. Se define por la ausencia de invierno térmico, con relativa poca variación de temperaturas durante el año. Las precipitaciones definen las estaciones. En efecto, las precipitaciones no se distribuyen de forma uniforme a lo largo del año, sino que presentan importantes variaciones estacionales, con un período de fuertes lluvias llamado invierno y un período seco llamado verano (Monasterio \& Molinillo, 2003).

Como todos los páramos andinos venezolanos, esta área está habitada principalmente por una población mestiza, descendientes de la mezcla entre españoles e indígenas, cuya actividad principal es la agricultura.

La metodología de este trabajo se basó en el trabajo etnográfico en las comunidades rurales, así como en la investigación en archivos y obras históricas. El análisis bibliográfico permitió identificar las principales fases de la historia agrícola de esta área de estudio, mientras que las entrevistas buscaron cubrir el período más reciente. En total, entre los años 2013 y 2019 se realizaron 65 entrevistas con agricultores y 30 con diferentes actores estratégicos de todo el estado de Mérida. También se realizaron varias entrevistas en el estado de Trujillo para obtener una visión general de los Andes venezolanos. Debido a la situación social en Venezuela, las entrevistas de 2019 se llevaron a cabo por teléfono.

En general, las entrevistas se centraron en la trayectoria personal del agricultor y en la caracterización de su explotación. El objetivo era reconstruir la evolución de la agricultura en relación con los factores políticos, económicos y sociales del área de estudio. Otras personas también proporcionaron información sobre la historia agrícola local, como autoridades locales, ONG, asociaciones, técnicos, entre otros actores.

\section{EL DESARROLLO DE LA HORTICULTURA DE REGADÍO EN LOS ANDES VENEZOLANOS}

\subsection{Renta petrolera, procesos de urbanización y declive agrícola}

Hasta las primeras décadas del siglo Xx, la economía de Venezuela fue principalmente agrícola. Este país era el segundo productor mundial de café, un cultivo que representaba al- 
rededor del $75 \%$ de las exportaciones y una parte significativa de los ingresos del Gobierno (Bergquist, 1988). La producción de café en Venezuela, que se localiza en gran parte en los Andes entre los 900 y 1.400 m s. n. m., cambió de forma considerable las condiciones de vida de los pueblos andinos, en particular en Mérida, donde se optimizaron las áreas sociales y la infraestructura del Estado (Robert, 1991).

Sin embargo, el descubrimiento de petróleo en el país desde la segunda década del siglo Xx tuvo consecuencias devastadoras para la agricultura andina. De hecho, durante la dictadura de Juan Vicente Gómez (1908-1935), el país pasó de una economía agrícola a una economía basada esencialmente en la explotación petrolera. Así, al final de la dictadura de Gómez, el petróleo representaba más del 85\% de las exportaciones deVenezuela, lo que convirtió a este país en uno de los mayores exportadores de petróleo del mundo (Pinto, 1966; Hernández, 2006).

\section{FIGURA 2}

Exportaciones petroleras y agrícolas en 1913, 1926 y 1936 (en millones de bolívares)

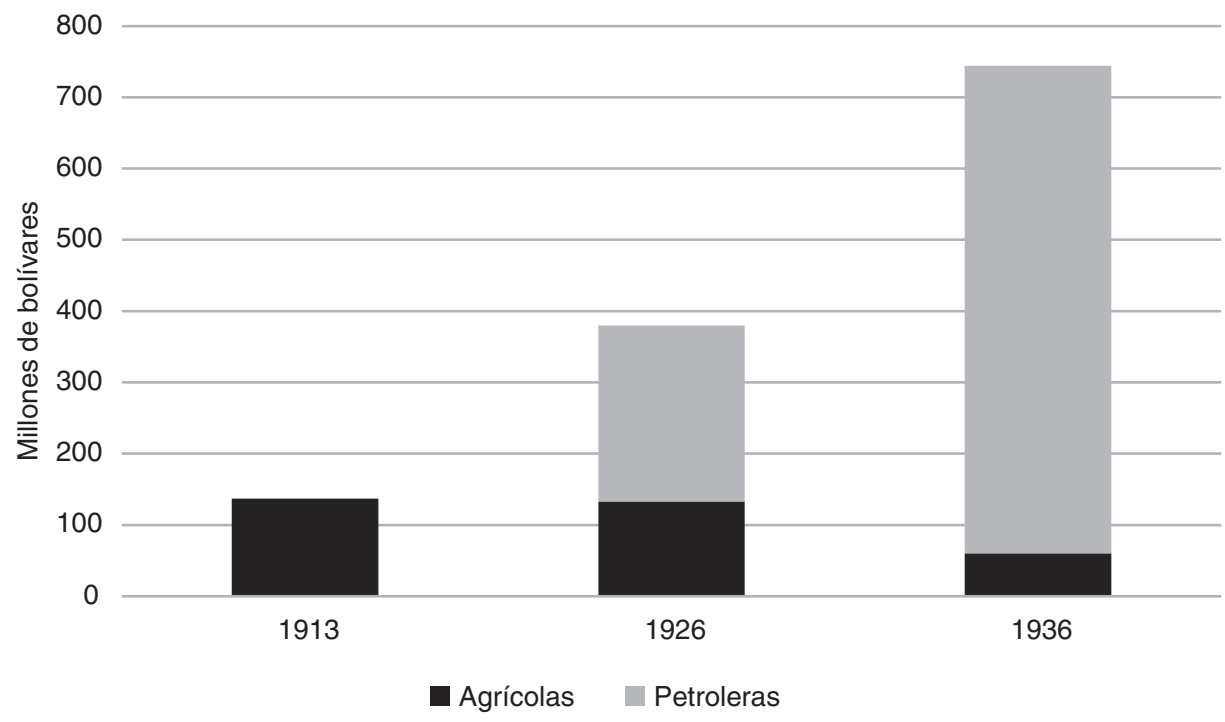

Fuente: Pinto (1966).

Ya en 1936, el político y escritor venezolano Arturo Uslar Pietri acuñó el término "sembrar el petróleo». En un artículo publicado el 14 de julio de 1936 como un editorial del diario Ahora, Uslar Pietri abogaba por la inversión de la riqueza petrolera -que él consideraba transitoria- en la agricultura, particularmente a través de créditos agrícolas, sistemas de riego y caminos rurales (Uslar Pietri, 2005). 
Sin embargo, en un país con las mayores reservas probadas de petróleo del mundo, el Estado se centró en la explotación de hidrocarburos, lo que dio lugar a lo que los especialistas llaman «enfermedad holandesa» (Ismail, 2010). Los síntomas no son otros que el aumento de los ingresos en un solo sector de la economía (aquí, la industria petrolera), en detrimento de otros sectores (agricultura e industria manufacturada) (Morales, 2002). Sin embargo, el aumento de los ingresos petroleros generó considerables entradas de divisas y, como consecuencia, la apreciación o la revaluación de su moneda. Este fenómeno hizo que los sectores productores y exportadores (como la agricultura) fueran más vulnerables y menos competitivos, dado que las importaciones eran baratas y las exportaciones costosas (Morales, 1985; Fardmanesh, 1991).

En la memoria colectiva de las comunidades rurales aún está presente el abandono de la agricultura tras el auge del petróleo. De hecho, aunque no había nacido en ese momento, un agricultor de Misintá nos cuenta cómo la agricultura andina se vio particularmente afectada por este fenómeno debido a la disminución del cultivo de café y cacao, cultivos que han contribuido al enriquecimiento de los Andes venezolanos:

«Gracias a que surgió el petróleo en Venezuela, abandonaron el campo de cacao, abandonaron el campo de café, abandonaron todos los campos y entonces los campesinos abandonaron sus campos y se fueron a los petroleros o se fueron a las grandes ciudades donde se administró el dinero del petróleo [...] el petróleo le ha hecho muchísimo bien a Venezuela, por supuesto que sí, pero también desde ese punto de vista, le ha hecho mal. Porque concentran su intención en el petróleo y dejaron a un lado lo que fue la agricultura, la ganadería, la pesca [...]» (Bladimir B., 35 años, Misintá, Venezuela, agosto de 2013).

Las zonas de mayor altitud de los Andes (más allá de los campos de café y de cacao) también experimentaron el proceso de industrialización y urbanización ligado a la renta petrolera. De hecho, en la década de 1950, la zona de estudio, el valle del Alto Chama, era considerada un área marginal. La agricultura, que era la principal actividad económica de los habitantes de este alto valle tropical, cubría parcialmente las necesidades alimentarias de la población local y no se exportaba. La producción agrícola se caracterizaba por una combinación de cultivos tradicionales (apio, papa negra, frijoles, haba) y cultivos heredados de la época colonial (trigo), muchos cultivados según las estaciones y el potencial natural del medio ambiente (Angéliaume-Descamps \& Tulet, 2009; Leroy et al., 2013).

En tal medida, la pobreza y la miseria se extendieron de manera generalizada en la zona (Tulet, 2002). En consecuencia, la población de esta zona de alta montaña experimentó 
las consecuencias de la emigración masiva a las grandes ciudades, en especial a la capital. La Figura 3 muestra que, a partir de los años cincuenta, la población urbana creció más que la rural, hasta alcanzar una diferencia significativa del 89\% frente al 11\% en 2013 .

FIGURA 3

Evolución de la población rural y urbana en Venezuela, 1936-2013

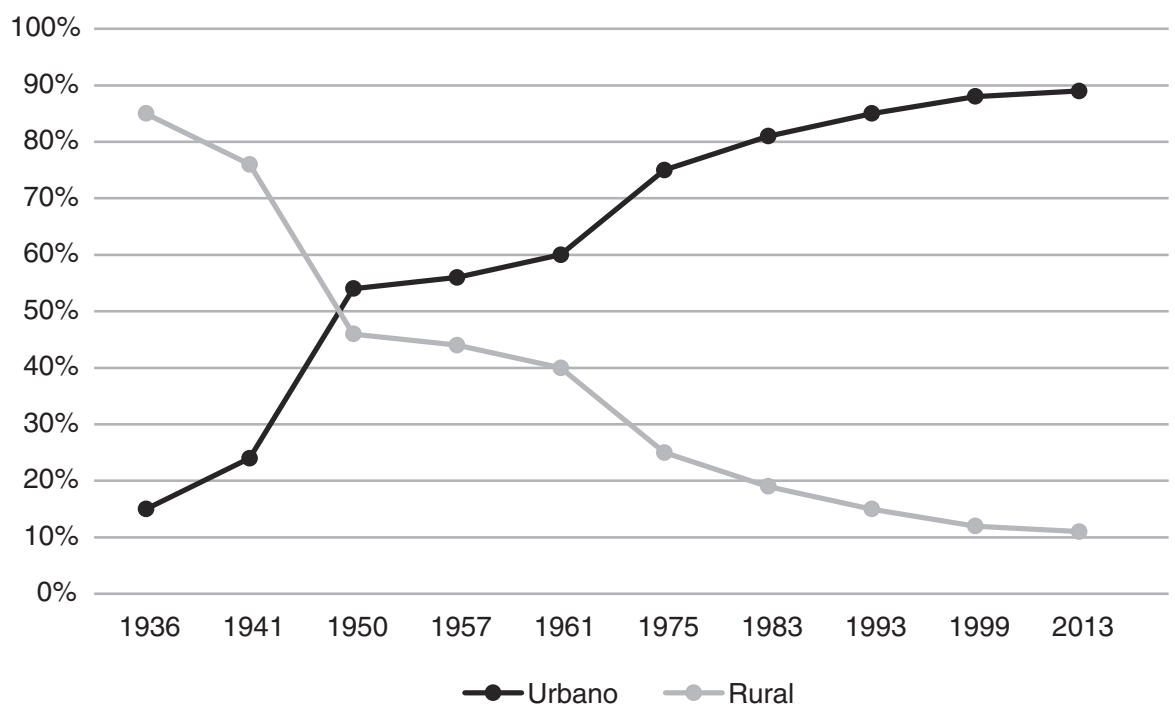

Fuente: a partir de datos de González Cortés (2016).

La llegada de un gran número de inmigrantes europeos, atraídos por el fuerte crecimiento del país en la década de 1950, también fue importante en este acelerado proceso de urbanización del país. Sin embargo, la contribución de estos extranjeros fue más socioeconómica que demográfica. En efecto, muchos de ellos habían sido agricultores en su país de origen y, por lo tanto, dominaban una tecnología agrícola desconocida para los campesinos venezolanos. De hecho, la llegada de los europeos se vio facilitada por diversas políticas migratorias para aprovechar sus conocimientos técnicos (Velázquez, 2001b).

\subsection{Inmigración, programas de desarrollo estatal y demanda del mercado: factores clave en la revolución de la horticultura}

Entre estos inmigrantes se destacaban los canarios, también llamados isleños para diferenciarlos de otros españoles (Tulet, 2002). Ellos fueron los principales actores de una nueva dinámica agrícola en la región andina venezolana. Huyendo de la guerra y de la dictadura española, trajeron con ellos todos los conocimientos técnicos agrícolas que habían 
adquirido en el viejo continente, así como una gran diversidad de insumos agrícolas: semillas importadas (Canadá, Alemania, Estados Unidos) que representaban la ventaja de tener un ciclo de producción de solo 90 días; papa blanca que sustituirá a la papa negra, con un ciclo de producción de 6 a 9 meses; fertilización mineral, productos fitosanitarios; y, finalmente, la práctica del riego por aspersión (Velázquez, 2001a).

«Los españoles, isleños pues, vinieron y traían sus prácticas y sus costumbres, entonces, llegaban y alquilaban terrenos, le quitaban la piedra y la broma y entonces sembraban diferentes a los de aquí a la papa, muy diferente y le aplicaban el abono, ya empezó ya a entrar el abono, y los pesticidas [...]» (Manuel R., 55 años, Mixteque, Venezuela, octubre de 2013).

En Mucuchíes, se dice que los isleños (aproximadamente veinte) llegaron en 1964 desde el estado de Lara. Para esos años, la tierra en el estado de Lara estaba siendo utilizada para la horticultura. Según el señor Rangel, «de repente, vieron que había tierra productiva aquí, todas estas llanuras... iy que había suficiente agua!». En efecto, los páramos, a consecuencia a sus condiciones bioclimáticas, se encuentran en una situación privilegiada para el establecimiento de la agricultura de riego intensivo. La presencia de temperaturas templadas en esas altas montañas $\left(15^{\circ}\right.$ de media anual) es una ventaja que permite sembrar cultivos que son imposibles de sembrar en el clima mucho más cálido y húmedo de las llanuras circundantes. Además, la riqueza hídrica y la fertilidad de los suelos del páramo son un activo fundamental para el desarrollo de una agricultura intensiva. $\mathrm{El}$ acceso al agua permite producir una nueva variedad de papas comerciales (papa blanca), además de asegurar una segunda o incluso una tercera cosecha en el año debido a las soleadas condiciones que ofrecen las latitudes tropicales.

El éxito económico de esta nueva agricultura provocó el entusiasmo de todas las comunidades (Velázquez, 2001b). Ahora bien, debido al saber hacer de los inmigrantes, los productores que habían recuperado sus tierras pudieron cultivar la papa blanca y enriquecerse.

"Uno se dio cuenta, y coño, pero esa gente viene de tan lejos, de Europa, a sembrar aquí, y mire de la noche a la mañana, madres quintas, madres carros, andaban más mejor que uno que vive aquí mismo, ¿y por qué nosotros no podemos hacer eso, teniendo las tierras nosotros mismos?» (Orlando, 63 años, Mixteque, Venezuela, noviembre de 2013).

Además de la innovación tecnológica, los inmigrantes modificaron toda la organización de la producción, la financiación agrícola y la comercialización de los productos. Un 
ejemplo de esto es que Agroisleña, la principal empresa comercializadora de insumos agrícolas del país, fue fundada en 1958 por un isleño inmigrante, Enrique Fraga Alfonso. Esta institución participaba en todas las etapas de la producción agrícola: financiaba, asistía y comercializaba las cosechas de los pequeños agricultores. La empresa vendía sus productos tanto en sus tiendas como en pequeñas empresas agrícolas o directamente en la finca del agricultor. Además, tenía un monopolio en el comercio de insumos químicos, a causa de una vasta red de contactos establecida por los inmigrantes canarios (Llambí \& Cousins, 1989).

Paralelamente al desarrollo de las prácticas agrícolas introducida por los isleños, surgieron al principio de los años 1970 nuevos cultivos de hortalizas (zanahorias, coliflores, brócoli, pimento, ajo, entre otras) en las zonas más bajas y menos empinadas de los valles altos andinos de Venezuela. Al respecto, algunos agricultores afirmaron que los inmigrantes italianos fueron los principales actores de esta dinámica agrícola en el valle del Alto Chama.

La introducción de estos nuevos cultivos marcó el comienzo de la revolución de la horticultura en los Andes venezolanos (Tulet, 2002). Sin embargo, el desarrollo de este nuevo modelo agrícola solo fue posible porque satisfacía la nueva demanda, especialmente urbana, del mercado de alimentos. De hecho, a partir de la década de 1950, la clase media se hizo cada vez más importante en Venezuela y los hábitos alimentarios comenzaron a verse influenciados por la población inmigrante (Velázquez, 2001b).

Si bien la experiencia de los inmigrantes jugó un papel fundamental en la difusión de nuevas prácticas de horticultura, el verdadero punto de inflexión en la agricultura andina venezolana fue impulsado por dos programas estatales de desarrollo: el Programa Subsidio Conservacionista (1959-1974) y el Programa Valles Altos (1974-1992). En ese momento, los ingresos petroleros permitieron que la economía venezolana tuviera un considerable superávit económico (Aguilar, 1978; Tulet, 1987).

El primer programa, Subsidio Conservacionista, tuvo el objetivo de controlar la erosión de la montaña mediante la creación de umbrales, muros de contención y reforestación. Las modalidades de acción se basaban esencialmente en el trabajo realizado por los agricultores a cambio de diversas subvenciones agrícolas. Si bien la prioridad del Gobierno nacional en ese momento era conservar estos valles altoandinos, también impulsó importantes transformaciones en el sistema de producción. Entre estas transformaciones la más significativa es el desarrollo de sistemas de riego colectivo por gravedad, cuyo objetivo era "concentrar el trabajo en las zonas más planas y menos vulnerables» (Tulet, 2002). 
La planificación y el diseño de los sistemas de riego fueron llevados a cabo por técnicos e ingenieros del Ministerio de Agricultura y Cría (MAC), y la mano de obra principalmente por agricultores. Además de desarrollar las prácticas de riego, el programa alentó la difusión del paquete tecnológico (semillas, insumos) mediante el asesoramiento y la demostración de los técnicos del MAC (Aguilar, 1978).

En 1974, se puso en marcha un nuevo programa de desarrollo agrícola para continuar el desarrollo de los valles andinos y la construcción de sistemas de riego por gravedad. El programa fue llevado a cabo inicialmente por una multitud de instituciones estatales, entre ellas Corpoandes, el Ministerio de Agricultura y la gobernación del estado de Mérida, lo que permitió invertir en ciertas infraestructuras distintas de los sistemas de riego (infraestructuras viarias, entre otras).

\section{FIGURA 4}

\section{Evolución del número de sistemas de riego colectivo en el estado de Mérida, 1964-2004}

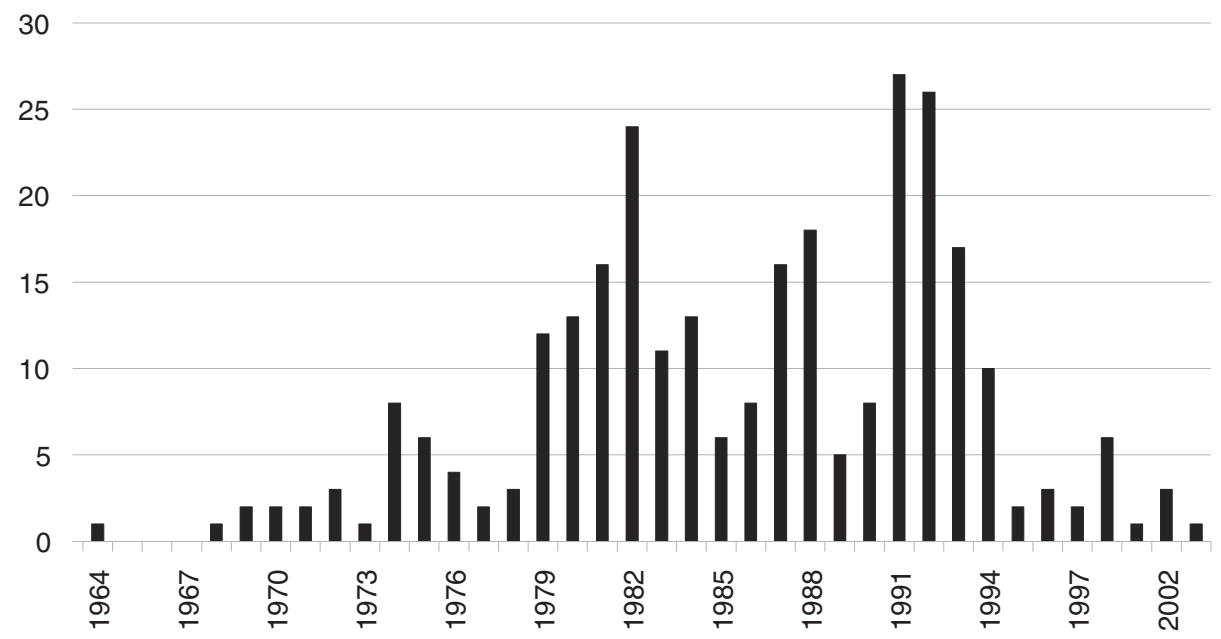

Fuente: Angéliaume-Descamps y Tulet (2009).

De manera similar al Programa Subsidio Conservacionista, el Progama Valles Altos movilizó la abundante mano de obra campesina para la construcción de sistemas de riego, a la vez que cubrió los costos de asistencia técnica e instalación. El proceso de asistencia técnica y la construcción de los sistemas de riego se vinculó a la creación de una organización de gestión del agua con un órgano institucional: el comité de riego. El objetivo del Gobierno era organizar a los agricultores para que pudieran gestionar el sistema de riego de forma colectiva y sostenible (Richer, 2005; Leroy, 2019). 
Este programa fue un verdadero éxito en todos los Andes venezolanos y marcó el punto culminante de Corpoandes. Así, uno de los principales resultados de estas iniciativas fue el desarrollo masivo del riego colectivo: por ejemplo, solo en el estado de Mérida, entre 1964 y 2004 se instalaron 284 sistemas de riego colectivo (Figura 4) que involucran a casi 8.400 agricultores y más de 18.400 hectáreas (Corpoandes, 2004; Angéliaume-Descamps \& Oballos, 2009; Angéliaume-Descamps \& Tulet, 2009).

En el municipio Rangel en la actualidad hay 40 perímetros de riego colectivo, que en su mayoría dependen de un comité de riego. No son áreas extensas, ya que cubren entre 9 y 150 hectáreas, pero están presentes en todo el paisaje agrícola: en las laderas, en los conos aluviales o en las terrazas del valle del Alto Chama (Smith \& Romero, 2012; Angéliaume-Descamps \& Oballos, 2009).

\subsection{Una agricultura intensiva y familiar}

A partir de la década de 1960, los valles altoandinos venezolanos cambiaron su función: de zonas improductivas donde la agricultura tradicional se había desarrollado durante siglos (especialmente bajo la influencia de la colonización española), se convirtieron en zonas de agricultura de regadío intensiva cuya producción se orientaba hacia nuevas demandas de productos de la horticultura (papas de ciclo corto, zanahorias, ajo, fresas, coliflor, brócoli, pepinos, entre otros). La mayor parte de la producción agrícola se destina a los grandes centros de abastecimiento de las grandes ciudades (Valencia, Maracay, Maracaibo) y en particular a Caracas.

El estado de Mérida se convirtió rápidamente en una de las principales áreas de producción agrícola del país: por ejemplo, para el 2001 (menos de diez años después de la finalización del Programa Valles Altos), el estado producía el 54,48\% del ajo, el 55,48\% de la papa, el $76,95 \%$ de la coliflor y el $82,30 \%$ de la zanahoria de producción nacional. El estado ocupaba en este periodo el $34,6 \%$ de la superficie nacional dedicada a la horticultura (Angéliaume-Descamps \& Oballos, 2009).

Es menester decir que las tierras de los páramos, por su condición bioclimática, son muy productivas, como es el caso del municipio Rangel, una de las principales zonas de cultivo de hortalizas en los Andes de Mérida. Como se puede observar en la Figura 5, desde los años noventa la superficie sembrada en el municipio Rangel aumentó de forma sostenida. En total, la superficie sembrada se duplicó con creces, pasando de 2.079 hectáreas a 4.800 hectáreas en solo 16 años. En el municipio Rangel los principales productos 
son la papa, el ajo y la zanahoria, que en 2010 representaron el 90,3\% de la producción total del municipio (Smith \& Romero, 2012).

FIGURA 5

Evolución de la superficie sembrada en el municipio Rangel, 1993-2010

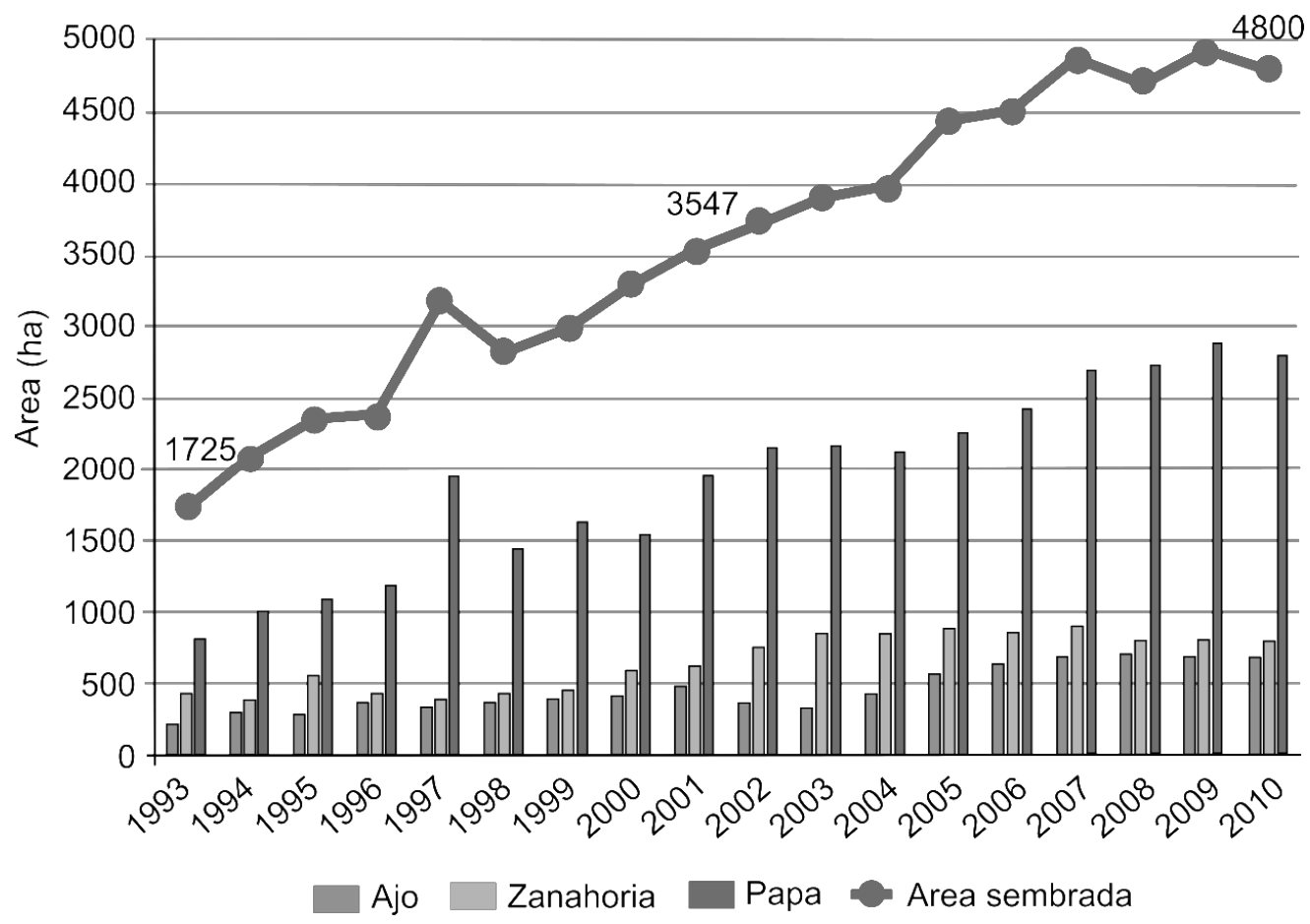

Fuente: Smith y Romero (2012).

En términos generales, el aumento de la producción agrícola tras la revolución de la horticultura de regadío se asoció a una mejora de las condiciones de vida de la población, a la consolidación de las explotaciones familiares, al aumento del capital y, en menor medida, a un aumento de la seguridad de la producción (Tulet, 2002). Una vez considerada tierra de emigración, el páramo del municipio Rangel se convirtió en un espacio atractivo y una fuente de riqueza de un nivel raramente alcanzado. Ya no se trata de buscar un ingreso en la ciudad, sino quedarse en los páramos (Tulet, 1999). Por otro lado, esta dinámica está vinculada a un proceso de sucesión por herencia, lo que da lugar a una división importante de la superficie apropiada, dado que se divide entre los hijos la propiedad del padre, recibiendo cada uno parcelas más pequeñas. 
Hoy en día el espacio ocupado por las explotaciones más pequeñas, de menos de cinco hectáreas, es mayor. Los propietarios son, por lo tanto, abrumadoramente pequeños. En algunos casos se puede hablar incluso de la preeminencia de los microproductores o propietarios de menos de una hectárea. De hecho, como se puede observar en la Tabla 1, en ambas comunidades predominan las fincas muy pequeñas, con fincas de menos de una hectárea que representan el 56\% del total de las fincas en Misintá y el 69\% en Mixteque (Smith et al., 2007).

\section{TABLA 1}

Tamaño y proporción de las fincas en Misintá y Mixteque, 2006

\begin{tabular}{lcrrr}
\hline & \multicolumn{2}{c}{ Misintá } & \multicolumn{2}{c}{ Mixteque } \\
Tamaño de las fincas (ha) & Número de fincas & $\%$ & Número de fincas & $\%$ \\
\hline Menos de 0,5 ha & 44 & 38,0 & 93 & 59,6 \\
0,5-1 ha & 21 & 18,1 & 16 & 10,2 \\
1-2,5 ha & 25 & 21,6 & 17 & 10,9 \\
$2,5-5$ ha & 8 & 6,9 & 11 & 7,0 \\
5-10 ha & 9 & 7,7 & 7 & 4,5 \\
Más de 10 ha & 9 & 7,7 & 12 & 7,7 \\
Total & $\mathbf{1 1 6}$ & $\mathbf{1 0 0}$ & $\mathbf{1 5 6}$ & $\mathbf{1 0 0}$ \\
\hline
\end{tabular}

Fuente: Smith et al. (2007).

Si bien la transformación de la agricultura impulsó considerablemente la economía de los páramos, en particular al integrarla de manera directa en el mercado, también dio lugar a la monetización de la unidad agrícola familiar. El acceso a los recursos monetarios fue muy beneficioso para las poblaciones rurales, que finalmente pudieron beneficiarse de muchos servicios que antes estaban reservados a las élites urbanas. Sin embargo, la monetización de la agricultura familiar también puso fin a algunas prácticas tradicionales que eran fundamentales para la vida del campesino andino y su comunidad (Suárez, 1979). Como ocurrió con la desaparición de las prácticas de autoayuda (convite, mano vuelta y cayapa), que desaparecieron al mismo tiempo que la llegada de dinero, tal como nos explica este campesino de Mixteque:

"Ahorita no era como antes, cuando uno sembraba el trigo, íbamos en cayapa, yo iba y le ayudaba a usted, usted me ayudaba a mí, sin pagar sino, en cayapa a mano vuelta, se entendía así, ahora no, ahora es contratos y hay que pagar obrero y todo, ve por eso es que el trigo se ha dejado de sembrar» (Nektali D., 45 años, Mixteque, Venezuela, octubre de 2013).

Aunque la modernización de la agricultura familiar se materializó en el establecimiento de un modelo empresarial, esta dinámica no condujo a una ruptura de la relación entre 
el trabajo familiar y el trabajo remunerado en la explotación. Las explotaciones agrícolas siguen dependiendo de una abundante mano de obra familiar, aunque la participación de la familia ha disminuido a medida que la economía de mercado se ha desplegado. El trabajo de los obreros se reserva para las tareas más laboriosas, como la cosecha. Sin embargo, la mayoría de los productores se quejan de la escasez de la mano de obra y de los altos salarios que, en consecuencia, tienen que pagar a sus empleados, asumiendo esto como una de las principales limitaciones de su trabajo como agricultores.

A pesar de los cambios tecnológicos, las actividades agrícolas más básicas, como el arado, el deshierbe y la cosecha, cambiaron muy poco en las últimas décadas. En efecto, la yunta de bueyes, introducida por los españoles en el siglo XVI, es también la principal herramienta para trabajar la tierra, sobre todo por la fuerte pendiente de las parcelas.

Hoy en día la agricultura no consiste tanto en alimentar a la familia como en generar beneficios monetarios sustanciales. Si bien estos procesos permitieron a los pequeños agricultores integrarse en el mercado nacional, también condujeron a un alargamiento de la cadena de comercialización, en la que los intermediarios concentran la mayor parte del valor agregado.

Además, dado que la producción se destina a los principales mercados urbanos, los precios nunca son fijados por los agricultores, sino por los principales centros de abastecimiento, como el principal mercado de Coche en Venezuela. Por lo tanto, la intensificación de las actividades agrícolas también tuvo repercusiones socioeconómicas, en especial entre los agricultores más pobres, que pasaron a ser dependientes del mercado.

En las décadas de 1970 y 1980, algunos agricultores trataron de establecer sistemas de comercialización alternativos mediante la creación de cooperativas de productores agrícolas, que abarcaban las etapas entre la cosecha y la exportación. Sin embargo, con respecto a las redes de intermediarios, estas cadenas cortas frecuentemente han fracasado, en particular debido a la baja cultura empresarial en los socios y los directivos (Richer, 2005).

La horticultura también fue acompañada de importantes cambios en los métodos de producción, que han tenido un impacto en el medio ambiente (Angéliaume-Descamps \& Oballos, 2009). De hecho, debido a la multiplicación del número de cosechas, los suelos de los páramos están ahora severamente degradados. La disminución de la fertilidad ha sido compensada por el creciente uso de fertilizantes, especialmente de la llamada gallinaza (estiércol de gallina), con el correspondiente aumento de los costos de producción y una contaminación de suelos y aguas (Tulet, 2002). 
En los años noventa, después de un gran auge económico, la agricultura andina venezolana, y más particularmente, el cultivo de papa, entró en una profunda crisis debido a la aparición de plagas de insectos (gusano guatemalteco y gusano blanco) (Llambí \& Arias, 1997). Estas plagas debilitaron gravemente la agricultura y han marcado una dependencia de productos fitosanitarios cada vez más tóxicos, y, en ocasiones, hasta prohibidos como el DDT (diclorodifeniltricloroetano). Como resultado, el uso masivo de insumos agrícolas ha causado gran preocupación en los últimos años por el impacto que estas sustancias pueden tener en todas estas frágiles montañas y sus habitantes. Además, los recursos hídricos están sobreexplotados, en particular para abastecer los numerosos sistemas de riego (Leroy et al., 2013; Leroy, 2017).

Estas degradaciones ambientales fueron una fuente de conflicto entre los agricultores y las autoridades del Instituto Nacional de Parques (Inparques), en especial después de la creación de los planes de manejo y los reglamentos de uso para los dos parques nacionales (desde 1992, para el de Sierra Nevada, y 1995, para el de Sierra de La Culata). La introducción de medidas restrictivas para las comunidades rurales en ese momento provocó desacuerdos, tensiones e incluso enfrentamientos, en particular en la sierra Nevada ${ }^{1}$.

\subsection{La consolidación de un movimiento comunitario y ambientalista}

Si bien la intensificación agrícola impulsada durante las últimas décadas en los Andes venezolanos produjo profundos cambios socioeconómicos y ambientales, también llevó a varios procesos organizativos que permitieron formular propuestas de desarrollo que combinan objetivos económicos, sociales y ambientales (Richer, 2005).

Por ejemplo, tan pronto como se establecieron a principios de la década de 1970 los comités de riego creados para gestionar los sistemas de riego colectivo, estos asumieron casi la totalidad de los proyectos de utilidad colectiva de las comunidades, sobre todo porque la ausencia de inversiones gubernamentales obligaba a los agricultores a organizarse colectivamente para ciertas obras de interés común.

«El comité no solo estaba allí para resolver el sistema de riego y mejorar la agricultura, sino también para resolver todos los demás problemas que presenta la

1. Las comunidades rurales de la sierra Nevada, como la de Mixteque, se ubican integralmente dentro del Parque Nacional Sierra Nevada, mientras que las comunidades rurales de la sierra de La Culata, como la de Misintá, se ubican fuera del Parque Nacional Sierra de La Culata. 
comunidad. Otras necesidades, necesidades de vivienda, carreteras, electricidad, todas estas necesidades» (Augusto E., 65 años, Misintá, Venezuela, agosto de 2013).

Los comités de riego se han basado siempre en relaciones de ayuda mutua (cayapa, mano vuelta, convite), por lo que hoy sigue presente el sistema de solidaridad y reciprocidad en los Andes venezolanos. Estos, además de sus papeles económicos y sociales, fueron una puerta de entrada a diversas ONG, asociaciones e instituciones académicas enfocadas a la protección del medio ambiente. Este fue, por ejemplo, el caso de la ONG ambientalista Programa Andes Tropicales (PAT), que inició su intervención en el municipio Rangel en la década de 1990, mediante la difusión de prácticas agrícolas alternativas. Esta ONG también sentó las bases de la Asociación de Productores Integrales del Páramo (Proinpa), una asociación de productores que trabaja en favor de una agricultura más sostenible, más concretamente, de la agroecología (Romero \& Romero, 2007).

Más recientemente, la Asociación de Coordinadores del Ambiente por los Agricultores del municipio Rangel (ACAR) (1999) logró movilizar más de tres mil agricultores de los comités de riego del municipio Rangel para que trabajen en la preservación de los humedales, con acciones de restauración y el establecimiento de perímetros de protección. Al mismo tiempo, la ACAR desempeñó a nivel municipal un papel importante en el desarrollo de la educación ambiental basada en la recuperación de la cultura ancestral del páramo, y en el respeto y el amor por "la madre naturaleza» (Angéliaume-Descamps, Blot \& Leroy, 2013).

Durante los últimos 15 años, se desarrollaron varios proyectos de cooperación entre los comités de riego y la comunidad universitaria. Este fue particularmente el caso del Instituto de Ciencias Ambientales y Ecológicas (ICAE) de la Universidad de los Andes de Mérida, que participó en el diseño de estrategias de conservación comunitaria, en el mapeo y manejo participativo de tierras, en la educación ambiental y en la revalorización de la cultura ancestral del páramo (Llambí et al., 2005; Leroy, 2017).

Más allá de su transformación como espacio de producción intensiva, los Andes venezolanos, y más particularmente el municipio Rangel, vieron así surgir varios incentivos locales que han fomentado la cooperación de los agricultores y la gestión de los problemas ambientales. 


\title{
4. DE LA REVOLUCIÓN BOLIVARIANA A LA CRISIS
}

\subsection{La ilusión de la soberanía alimentaria}

Los programas de desarrollo de Subsidio Conservacionista y Valles Altos, establecidos en los años sesenta del siglo pasado, fueron un verdadero éxito en los Andes venezolanos. La abundancia de fondos para el diseño y la construcción de nuevos sistemas de riego permitió dinamizar estas zonas rurales anteriormente abandonadas. En este caso, se puede decir que el petróleo fue «sembrado» (Tulet, 2002).

Pero el retiro del Estado venezolano de las zonas rurales a partir de 1989 (impulsado por los ajustes estructurales del FMI y del Banco Mundial) marcó un punto de inflexión para la agricultura en los Andes venezolanos (Llambí \& Arias, 1997; Gutiérrez, 1998). A partir de esa fecha, la influencia de Corpoandes y del Ministerio de Agricultura disminuyó de forma significativa y las comunidades rurales se vieron empujadas a ser autónomas, particularmente en la gestión de los sistemas de riego colectivo (Richer, 2005). Incluso, es común que en la memoria de las comunidades rurales se recuerde esta época como un momento histórico en el que fueron abandonados por el Gobierno venezolano.

\begin{abstract}
"A quién le va a importar la agricultura teniendo todo el dinero del mundo que se puede sacar de un pozo petrolero. Entonces en los gobiernos anteriores, digamos que nos abandonaron [...]» (Bladimir B., 35 años, Misintá, Venezuela, agosto de 2013).
\end{abstract}

Ahora bien, durante las reformas neoliberales del gobierno de Carlos Andrés Pérez (1989-1993) el hambre y la desnutrición aumentaron en un contexto de creciente éxodo rural, agitación social y mayor dependencia de las importaciones de alimentos (Morales, 2009). Estos eventos sin duda tuvieron un papel importante en la elección del presidente Hugo Chávez en 1998 (López Maya \& Lander, 1999).

El mandato de Hugo Chávez Frías (1999-2013), caracterizado por una ideología socialista y populista, estuvo marcado por un crecimiento económico casi constante en toda Venezuela que logró durante varios años generar una idea de prosperidad que beneficiaría a sectores sociales tradicionalmente olvidados, como los campesinos (Puente \& Simont, 2018).

Para superar la dependencia de las importaciones agroalimentarias, el Estado hizo de la "soberanía alimentaria» una de las políticas más emblemáticas de la «revolución bolivariana» (Parker, 2008; McKay, Nehring \& Walsh-Dilley, 2014; Enríquez \& Newman, 
2016; Schiavoni, 2017; Lubbock, 2020), cuyo objetivo era el aseguramiento de un sistema de producción agrícola ambientalmente sustentable y socialmente soberano (Enríquez \& Newman, 2016).

Si bien la Constitución de 1999 proporcionó una base jurídica para la construcción de la "soberanía alimentaria», esta tuvo como primer objetivo alcanzar la "seguridad alimentaria» (Enríquez \& Newman, 2016), esto es: la garantía del acceso suficiente y estable de la población a los alimentos en el contexto nacional (República Bolivariana de Venezuela, 1999: art. 305).

Para ello, el Estado desarrolló una serie de nuevas instituciones, medidas de gobierno y estructuras políticas (Ley de Tierras y Desarrollo Agrario, 2001) para movilizar la tierra, la población y el crédito (Purcell, 2017; Lavelle, 2013). Para el 2013, el Estado había recuperado 6,34 millones de hectáreas y regularizado 10,2 millones de hectáreas a nivel nacional (Purcell, 2017). Aunque parte de estas tierras se redistribuyó a los individuos, el Estado prefirió apoyar a las cooperativas y asociaciones civiles para promover un enfoque más colectivo de la producción (Enríquez \& Newman, 2016).

Uno de los retos iniciales e inmediatos de la Revolución Bolivariana fue asegurar las necesidades alimentarias de la población del país, que era mayoritariamente urbana (88\%), lo que se logró en gran medida a través de programas sociales (misiones) y red de alimentos subvencionados (MERCAL) promovidos por el Gobierno (Schiavoni, 2015; Purcell, 2017).

Si bien la Constitución de 1999 sentó las bases de una política nacional de soberanía alimentaria, fue realmente a partir del 2008 cuando el Gobierno declaró su objetivo de lograr la soberanía alimentaria mediante la Ley Orgánica de Seguridad y Soberanía Alimentaria (McKay, Nehring \& Walsh-Dilley, 2014; República Bolivariana de Venezuela, 2008). Este objetivo se tradujo en la promoción de un enfoque agroecológico de la agricultura (Schiavoni, 2015; Enríquez \& Newman, 2016), que consiste en utilizar medios no químicos para controlar las plagas y mantener la fertilidad del suelo, revalidando al mismo tiempo las prácticas de producción tradicionales y en pequeña escala (Altieri \& Toledo, 2011).

La población agricultora de la región andina venezolana -particularmente la del municipio Rangel- participó en varios experimentos interesantes destinados a reducir la dependencia de semillas extranjeras y fomentar las prácticas agroecológicas comunitarias. Dos instituciones estatales, el Instituto Nacional de Investigación Agropecuaria (INIA) y la Unidad Territorial del Ministerio del Poder Popular para la Educación, Ciencia yTec- 
nología (Fundacite), colaboraron con la asociación de productores Proinpa para promover la producción de variedades de papa autóctonas como parte del Plan Nacional de Semillas de Papa. El objetivo era producir "semillas libres de enfermedades (que permiten disminuir el uso de agrotóxicos) [...] y de alto potencial de rendimiento» (Raphael R., 43 años, coordinador de Proinpa, Venezuela, noviembre de 2013).

Esta iniciativa dio como resultado la certificación de una nueva variedad nacional de papa y la transferencia de nuevos conocimientos y técnicas a los miembros de la comunidad (Romero \& Monasterio, 2005; Romero \& Romero, 2007). En 2013, según su coordinador, Proinpa produjo el $85 \%$ de las semillas de papa prebásica de Venezuela. La ventaja de estas variedades era salir de la dependencia de las importaciones, pero también limitar el uso de insumos agrícolas. Sin embargo, estas variedades no pueden competir con la variedad de semillas canadienses en términos de costo o productividad, lo que limita su adopción por las comunidades rurales (Purcell, 2017). En efecto, los productores de papas del municipio Rangel ven en la importación la forma inmediata y «segura» de renovar sus tubérculos semilleros, una vez agotados los ciclos de replicación en sus propias parcelas (Romero \& Monasterio, 2005). Por esta razón, la asociación reúne solo a unos pocos individuos (50) con áreas muy reducidas.

A pesar de la voluntad del Estado de garantizar un sistema de producción y la autosuficiencia nacional en semillas, en particular a través del Plan Nacional de Semillas de Papa impulsado por el INIA, Venezuela no ha superado su dependencia de la importación de semillas. En consecuencia, el Estado venezolano, obligado a la importación masiva de semillas, obstaculizó indirectamente el desarrollo y el objetivo de autosuficiencia que planteaba el Plan Nacional de Semillas de Papa (Romero \& Monasterio, 2005). Además, si bien el objetivo del Gobierno venezolano era el de potenciar la seguridad y la soberanía alimentaria mediante del desarrollo de la agroecología, el ejemplo de Proinpa muestra que la difusión de estas prácticas en las comunidades rurales es particularmente difícil, debido a situaciones de «bloqueo sociotécnico» en torno a sistemas de producción especializados e intensivos en insumos químicos, como lo señaló el coordinador de la asociación.

$\mathrm{Al}$ igual que esta experiencia en los Andes venezolanos, las iniciativas gubernamentales de soberanía tuvieron una corta vida y no pudieron apoyar la soberanía alimentaria (Purcell, 2017). Las políticas gubernamentales se centraron en el sector petrolero, lo que llevó al abandono y el subdesarrollo del sector agrícola, hasta el punto de que la mayoría de los productos agroalimentarios deben ser importados del exterior dada la baja capacidad productiva del sector en este país (Enríquez \& Newman, 2016). Así, Venezuela pasó de tener 1.765.749.223 USD (dólar de los Estados Unidos) de importaciones agro- 
alimentarias en 1998 a 10.045.089.256 USD en 2013 (Fonseca Sánchez \& Gutiérrez, 2017).

Estos datos demuestran que los objetivos de la soberanía alimentaria nunca fueron alcanzados, y dieron paso a una política de seguridad alimentaria por todos los medios (Purcell, 2017). Para Kappeler (2013), la producción nacional a través de la producción agrícola de pequeños productores y basada sobre las cooperativas fue un fracaso.

Si bien la economía rentista de Venezuela ha apoyado la formación de un complejo agroalimentario dependiente de las importaciones (Purcell, 2013), este fenómeno se incrementó drásticamente bajo el gobierno de Chávez, debido a algunas políticas inconsistentes. Así, la aplicación de controles cambiarios en 2003 para evitar la fuga de capitales y reactivar la economía nacional tuvo un impacto considerable en la economía del país. La creación de un tipo de cambio oficial elevado provocó un aumento de las importaciones y la destrucción del aparato de mercado de la economía (Puente \& Simont, 2018). Al mismo tiempo, este sistema ha creado un mercado negro para las principales monedas (dólar y euro).

Temiendo que todos los productos se encarecieran, el Ejecutivo también decidió imponer controles de precios a varios alimentos: arroz, avena y preparaciones derivadas, harina de trigo, pasta, pan de trigo, carne, pollo, entre otros. Sin embargo, los precios fijados por el Gobierno eran generalmente muy bajos y no permitían a los agricultores reembolsar los costes de producción. Como resultado, algunas fincas reportaron pérdidas significativas y decidieron cerrar (Lezama, 2019).

Aunque el sector agrícola en su conjunto se vio gravemente debilitado por estas medidas (Kappeler, 2013; Purcell, 2017), la producción de hortalizas (ajo, zanahoria, pimentón, cebolla...) y de papa $^{2}$, localizada principalmente en los Andes, ha aumentado a nivel nacional, pero también en el municipio Rangel (véase Figura 5). Así, la producción nacional de hortaliza aumentó de 1.008.797 toneladas en 1998 a 1.717 .475 toneladas en 2015, y la producción de papas de 322.141 toneladas en 1998 a 602.522 toneladas en 2015, según datos de la Confederación de Asociaciones de Productores Agropecuarios (Fedeagro). Este aumento se explica por el hecho de que no hay un control de precios para las frutas y hortalizas, sino subsidios a los productores en el lugar de producción (Purcell, 2017). También es importante destacar que los productos vegetales son rápidamente

2. Aunque la papa puede considerarse una hortaliza, los agricultores de los Andes, así como el sistema de clasificación utilizado por Fedeagro, la diferencian de este tipo de producción y la clasifican como "tubérculo». 
perecederos, lo que dificulta su importación. Sin embargo, a partir de principios de 2010 la agricultura andina venezolana se vio particularmente afectada por una nueva medida política.

En octubre de 2010, el presidente de Venezuela firmó un decreto para nacionalizar la empresa privada Agroisleña, el principal proveedor de insumos agrícolas del país. Para el Gobierno, las razones de esta expropiación eran numerosas: competencia desleal, especulación e incumplimiento de las normas ambientales (Orhangazi, 2014). La nacionalización de Agroisleña es el resultado de una política de expropiación sin precedentes implementada desde 1999. El objetivo es que la República Bolivariana de Venezuela sea autosuficiente (soberanía), pero también que pueda resistir cualquier ataque externo, particularmente vinculado al capitalismo (Estados Unidos, la oligarquía, la derecha). Los motivos de la expropiación fueron, por tanto, económicos, sociales y, en particular, políticos, como lo señala el director de Agropatria de Trujillo:

"¿Qué pasaría en el agro venezolano si esta empresa hoy también estuviera en manos de la derecha? Esta empresa estuviera sumada a la guerra económica en contra del país, esta empresa a nivel nacional es un punto neurálgico para la producción de alimentos» (Trujillo, mayo de 2015).

La expropiación de Agroisleña fue el punto de inflexión más importante en la agricultura venezolana en los últimos veinte años. Su sucesor desde el Gobierno, Agropatria, fue incapaz hasta ahora de administrar e iniciar la producción y comercialización de insumos y semillas agroquímicas. La mayoría de los insumos más tóxicos fueron eliminándose de la cadena de producción, lo que limita la contaminación ambiental. Sin embargo, nunca se preparó a los agricultores para este cambio tan rápido. El Estado nunca tuvo la capacidad organizativa y profesional para gestionar la transición, lo que ha creado importantes trastornos logísticos y numerosos casos de corrupción (Purcell, 2017).

De hecho, desde la creación de Agropatria los agricultores tienen que soportar largas filas para poder comprar productos en cantidades limitadas, porque, al igual que los productos vendidos a precios regulados (pasta, arroz, aceite, entre otros), los insumos agrícolas son racionados por el Estado. De hecho, la escasez creó un mercado paralelo más lucrativo. En 2014, los términos bachaqueo y bachaquero se añadieron al léxico popular venezolano para describir la práctica de la reventa de bienes públicos a precios controlados con fines de lucro. Así, por ejemplo, Agropatria debería vender sus productos a precios justos regulados, alrededor de un $30 \%$ por debajo de la tasa del mercado privado (Purcell, 2017), pero, en noviembre de 2014, varios agricultores nos dijeron que tenían 
que comprar estos productos en el mercado negro, entre cinco y seis veces el precio establecido por Agropatria. Los campesinos no tienen otra alternativa, ya que los sistemas de producción de hortalizas en los Andes son particularmente vulnerables a las amenazas fitopatológicas, como lo señala esta agricultora:

\begin{abstract}
«Con la expropiación de Agroisleña, cambió totalmente la agricultura en Venezuela. El acceso a los agroquímicos es muy fuerte, entonces uno tiene que comprarlo en el mercado negro a como estén, el precio que les pongan uno los necesita, los cultivos no esperan, uno tiene que buscar los productos, es muy complicado» (Asmeiry, 34 años, Misintá, Venezuela, noviembre de 2014).
\end{abstract}

La reventa de productos a precios regulados exacerbó en gran medida la escasez de insumos agrícolas en Venezuela, ya que muchos productos fueron revendidos en Colombia, lo que generó enormes ganancias para los contrabandistas. Debido a su proximidad a la frontera con Colombia, los Andes venezolanos se vieron particularmente afectados por este fenómeno. En nuestras entrevistas, muchos agricultores informaron que habían perdido sus cosechas o habían decidido no sembrar debido al riesgo económico asociado con la escasez de insumos.

La expropiación de Agroisleña es una de las políticas, junto con los controles cambiarios y de precios, que debilitó la agricultura venezolana. Como resultado, Purcell (2017) afirma que «La reproducción del capitalismo rentista por parte del Estado bolivariano ha dado lugar a un mundo distorsionado de precios y valores y ha llevado a Venezuela hasta el punto más lejano imaginable de la autosuficiencia alimentaria nacional».

\title{
4.2. La agricultura andina devastada por la crisis
}

Desde 2013, Venezuela está atravesando una crisis económica, política y social sin precedentes. En un país rico en petróleo (el 96\% de las exportaciones provienen de la venta de petróleo) y afectado por la caída de los precios del petróleo, la economía está experimentando una inflación galopante y la población una grave escasez de productos básicos cuyo desenlace parece interminable (Puente \& Simont, 2018).

Aunque los precios del petróleo se recuperaron a partir de $2016^{3}$, una fuerte caída en la producción venezolana impidió un repunte de los ingresos (OPEC, 2018). Según da-

3. Según cifras oficiales, el suministro de petróleo de Venezuela, que hace diez años era de 3,2 millones de barriles diarios, era de sólo 1,03 millones de barriles en abril (OPEC, 2018). 
tos del Banco Central de Venezuela (BCV), la inflación fue del 274,4\% en 2016, 862,6\% en 2017 y 130.060,2\% en 2018 (BCV, 2019).

En este contexto económico, la moneda nacional, el bolívar, está perdiendo valor cada día. Como resultado, el Gobierno llevó a cabo una conversión de moneda en 2018, que consistió en llamar bolívar soberano a la moneda local y eliminar cinco ceros, para hacerla circular en denominaciones más adecuadas para la hiperinflación. Pero la explosión del dólar en el mercado paralelo ha acabado por socavar la confianza y destruir el valor de la moneda nacional (Vera, 2018).

En este entorno hiperinflacionario, las importaciones disminuyeron de 57.183 millones de dólares en 2013 a 14.866 millones de dólares en 2018 (BCV, 2019), lo que explica la grave escasez de productos básicos, como alimentos y medicamentos. Nicolás Maduro, quien llegó al poder en 2013 como vicepresidente de Hugo Chávez, atribuye la crisis económica del país a las sanciones financieras impuestas por Estados Unidos a Venezuela y a su compañía petrolera nacional, Petróleos de Venezuela (PDVSA).

La crisis económica y política en el país se ha convertido en una compleja emergencia humanitaria con amplias repercusiones regionales. Se estima que 4,5 millones de venezolanos emigraron debido a la crisis humanitaria, quienes en su mayoría se refugiaron en países de América Latina y el Caribe (ACNUR, 2019). Según la Encuesta de Condiciones de Vida (Encovi) publicada anualmente por un consorcio de universidades venezolanas, el $80 \%$ de los hogares encuestados se encontraban en situación de inseguridad alimentaria y más del $60 \%$ de la población vivía en extrema pobreza (Universidad Central de Venezuela, Universidad Católica Andrés Bello \& Universidad Simón Bolivar, 2018).

La agricultura, como todos los sectores económicos del país, se vio afectada por la crisis, en particular debido al aumento de los costos de producción y a la grave escasez de insumos agrícolas. Las estadísticas del Ministerio de Agricultura ya no están disponibles desde 2015, lo que dificulta el diagnóstico, pero según los datos de la Fedeagro ${ }^{4}$, entre el 2008 y el 2019, la producción de maíz cayó en un $85 \%$; la de arroz en un $82 \%$; la de sorgo en un $99 \%$; la caña de azúcar en un $75 \%$; la papa en un $94 \%$; la de tomate en un $74 \%$; la de cebolla en un $86 \%$; el pimentón en un $90 \%$; y la de naranjas en un $92 \%$.

4. Los datos para 2019 se basan en estimaciones de Fedeagro realizadas con base a informantes claves, consumo de insumos, recepción de industrias, sus asociaciones y federaciones y datos del Ministerio de Agricultura no oficializados. 
Estas cifras concuerdan con los comentarios de varios agricultores que afirman que la producción de hortalizas en los Andes venezolanos ha disminuido en más de un $90 \%$. El cultivo de papa, uno de los principales alimentos básicos consumidos por los venezolanos, colapsó desde 2015, ya que no hay ninguna semilla de papa certificada (de Canadá u Holanda), lo que empuja a los agricultores a utilizar semillas de cultivos anteriores o cultivos de bajo rendimiento como las tatarabuelas. Alirio, un agricultor del estado de Trujillo, nos cuenta que «si sembraban 100 sacos de papa, ahora se siembran 10». En este contexto, se hace imposible satisfacer la demanda nacional de papas, porque el Estado ha logrado establecerse para activar la producción nacional de semillas.

La Figura 6, muestra la evolución de la producción de papas en Venezuela en los últimos 20 años. Se observa una primera caída de la producción en 2011, tras la expropiación de Agroisleña, y luego una segunda caída vinculada a la crisis venezolana, a partir de 2015.

\section{FIGURA 6}

Producción de papa en Venezuela, 1997-2019

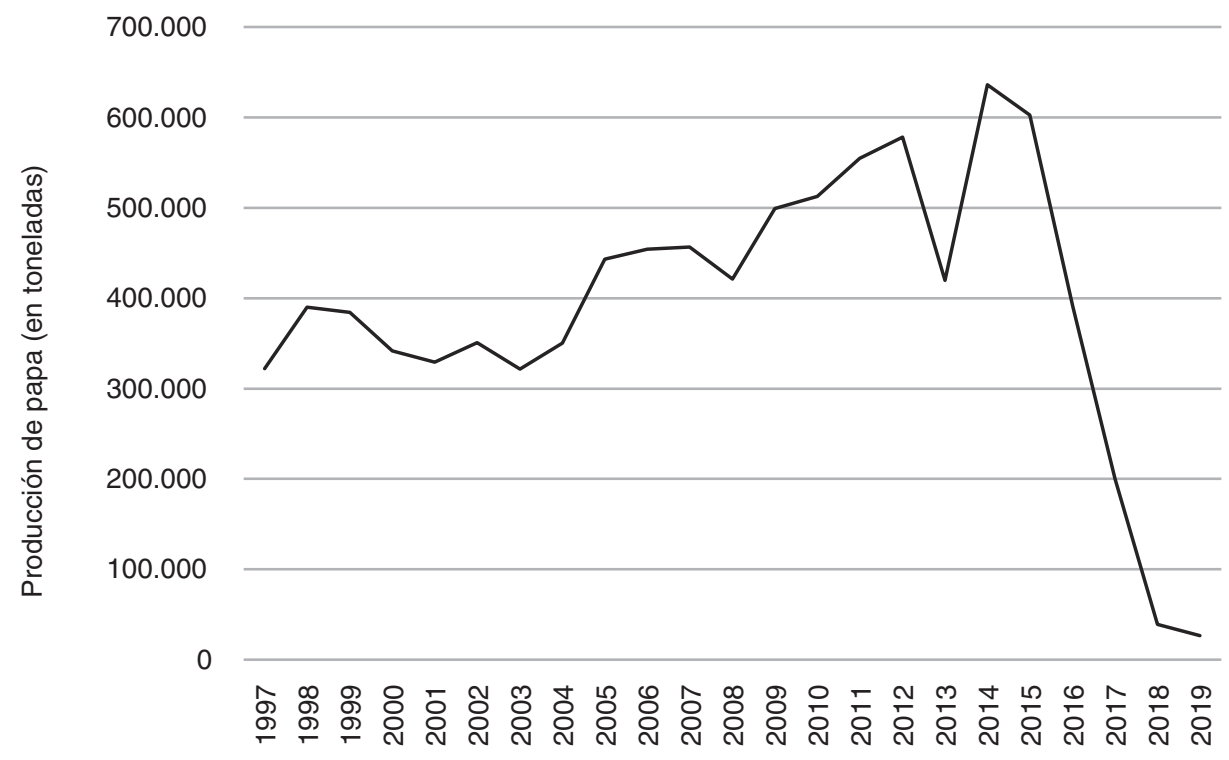

Fuente: a partir de los datos del MPPAT (1997-2015), FAOSTAT (2017) y Fedeagro (2019, 2020).

$\mathrm{El}$ acceso a pesticidas y fertilizantes es otro factor de crisis, porque los productos de Agropatria ya no llegan directamente a las manos de los agricultores, sino que se distribuyen a los grandes agricultores que tienen relaciones directas con los miembros del Gobierno. Frente a este fenómeno, muchos productores compran ahora insumos en Colombia y los 
introducen irregularmente en el país. Otros son abastecidos por casas agrícolas privadas, que también dependen de las importaciones de Colombia.

$\mathrm{El}$ acceso a los principales insumos agrícolas (fertilizantes, semillas y pesticidas) es ahora un problema central para los agricultores, especialmente en un contexto de dolarización de la economía. De hecho, todos los costos de producción se basan en monedas extranjeras (incluido el dólar), mientras que la venta de estos productos se realiza en bolívares (una moneda que se devalúa cada día). Por ejemplo, Madona nos dice que invirtió más de $\$ 150$ en semillas de repollo, pero no le permitió pagar los costos invertidos:

\begin{abstract}
«Nosotros hace poco sembramos repollo, y sacamos la cosecha, fue prácticamente pérdida, porque debíamos la semilla y el sobre de la semilla cuesta 150 dólares, que ni eso nos da la cosecha que nosotros trabajamos, abonamos, fumigamos, todo sacamos, pusimos en los sacos, llevamos la mercancía y ni siquiera eso da para comprar la semilla que vale 150 dólares. Hablamos de un tema que casi todo está dolarizado y cuando vendes la mercancía está en bolívares, entonces es bastante fuerte aquí el tema de la agricultura» (Madona P., Mixteque, Venezuela, septiembre de 2019).
\end{abstract}

En este contexto, la inversión representa un riesgo importante para el agricultor. Desafortunadamente en la actualidad no hay planes de crédito agrícola de los bancos públicos, ni siquiera en los bancos privados, debido a la hiperinflación. Esta es la razón por la que muchos agricultores deciden cambiar a cultivos que son menos arriesgados en términos de inversión; otros, en cambio, deciden inmigrar, como ya lo han hecho 4,5 millones de compatriotas. Sin embargo, como señalaron varios agricultores, este fenómeno aún no está muy presente en las zonas rurales de los Andes venezolanos (véase capítulo siguiente).

En cuanto a los agricultores que deciden seguir produciendo cultivos comerciales de hortaliza, estos tienen que hacer frente a varias limitaciones al momento de vender la producción, como la escasez de billetes o el coste del transporte. Esto en razón a que, en el contexto de crisis, los agricultores prefieren vender su producción directamente en el mercado, por temor a no recibir nunca su pago de intermediarios.

En este punto es menester indicar que en la actual situación de seguridad de Venezuela, que la hace uno de los países más peligrosos del mundo, cruzar su territorio para vender la producción es una verdadera odisea. Esto se evidencia en las numerosas escenas de saqueo de camiones agrícolas en las carreteras venezolanas; sumado a que, en un país con hiperinflación, las piezas de recambio para los vehículos de transporte (baterías, neumá- 
ticos, etc.) son prohibitivamente caras, lo que hace que el transporte sea muy caro; sin mencionar el alto deterioro de las carreteras, que están abandonadas por el Gobierno.

Desde 2018, la agricultura, como todos los sectores del país, se enfrenta a otra gran crisis: la ausencia de combustible. Este fenómeno paralizó el país desde mayo y llevó al colapso de la industria agrícola. La escasez de gasolina en el país con las mayores reservas de petróleo es solo la última manifestación de un colapso de los servicios gubernamentales que ha dejado a millones de personas sin un suministro fiable de electricidad, agua y gas butano.

El aumento galopante de todos estos costos de producción es pagado por el consumidor, quien, con un salario mínimo de 40.000 bolívares (unos dos dólares en el mercado negro), apenas puede comprar 1 kilogramo de cebollas a 12.000 bolívares, 1 kilogramo de papas a 9.000, 1 kilogramo de zanahorias a 6.000 y 1 kilogramo de tomates a 14.000 (en julio de 2019). Por eso están desapareciendo las famosas ferias de hortalizas en diferentes lugares y rincones de las ciudades y las pocas que se mantienen abiertas apenas ofrecen verduras frescas y carecen de compradores. Ante esta caída de la demanda de productos de horticultura, resulta impensable que los agricultores sigan invirtiendo en estos cultivos.

Por el momento, el Gobierno no ha podido hacer nada para detener el declive de la producción de hortalizas de los Andes venezolanos. Los recursos humanos, logísticos y técnicos de las instituciones del Estado se reducen prácticamente a nada. Hoy en día las instituciones del Ministerio de Agricultura no tienen la capacidad de ayudar a las comunidades rurales, debido a la falta de personal, de herramientas y de equipos.

\section{3. ¿Cómo se están adaptando las comunidades rurales de los Andes venezolanos a esta crisis?}

Mientras que la agricultura en los Andes venezolanos se ve particularmente afectada por la crisis, las comunidades rurales también están demostrando que son capaces de adaptarse a este fenómeno. Al vivir en una de las zonas agrícolas más productivas del país, son mucho menos vulnerables a la escasez de alimentos que el resto de la población venezolana.

A partir de 2015, los habitantes andinos comenzaron a cambiar sus sistemas de producción para garantizar la seguridad alimentaria del grupo o familia, al tiempo que no se descuidaban los cultivos más rentables, como el de la papa y la zanahoria. Pero una 
parte considerable de la producción (según algunos agricultores, entre el 80\% y el 90\%) se destina ahora a cultivos tradicionales (arvejas, caraotas y trigo). Se trata, por tanto, de una vuelta a la agricultura de subsistencia, que ha marcado esta zona durante siglos.

«Hay mucha gente que tiene sembrado su trigo, pero igual todavía siembran muchas habas, para la casa, y claro las alverjas, lo siembra la gente para el consumo de la casa, si se ha vuelto bastante ortodoxo la cuestión» (Argenis P., Misintá,Venezuela, septiembre de 2019).

El regreso a los sistemas de producción tradicionales fue bastante lógico, ya que estos cultivos no requieren insumos sintéticos, ni semillas certificadas ni mecanización. Además, pueden contar con abundante mano de obra familiar. De hecho, estos cultivos no habían sido totalmente abandonados por las comunidades rurales porque permiten variar la dieta de las poblaciones y también aprovechar al máximo los diferentes pisos agroecológicos de los Andes.

Si bien estas diferentes prácticas se acercan a los principios de la agroecología, es importante destacar que no fueron impulsadas por las políticas agrícolas del Gobierno; se trata de una adaptación de las comunidades rurales a la crisis venezolana que permite asegurar la subsistencia alimentaria o incluso la supervivencia alimentaria local en un país donde la precariedad es una amenaza de la que cada vez menos personas escapan.

Por lo tanto, este retorno a la agricultura tradicional está lejos de cumplir los objetivos de seguridad y soberanía alimentaria, ya que no permite abastecer los mercados urbanos con las hortalizas. De hecho, el contexto actual de escasez de combustible empuja a los agricultores a concentrar la venta de su pequeña producción agrícola en los municipios. Como en la actualidad no pueden utilizar sus vehículos motorizados, utilizan cada vez más sus animales (bueyes) como medio de transporte.

Ante el problema del aumento de la inflación y de la falta de liquidez, están reapareciendo ciertas prácticas, como el trueque y la ayuda mutua. Por ejemplo, los agricultores, con el fin de diversificar sus alimentos, a menudo intercambian una parte de su cosecha cuando la producción lo permite. El trabajo también se paga con la alimentación. Los trabajadores prefieren volver a casa con unas pocas papas y unas bolsitas de trigo en lugar de una gran cantidad de billetes que no valdrán mucho en unos pocos días.

La cayapa y mano vuelta, durante mucho tiempo en decadencia, pero nunca abandonados por las sociedades rurales, volvieron a ser centrales en los Andes venezolanos, 
lo que permite compensar la ausencia de mano de obra y enfrentar el fenómeno de la desmonetización de la economía agrícola. Generalmente estas relaciones de ayuda mutua se revelan dentro de la unidad familiar, pero también con los vecinos y amigos más cercanos. Demuestran que las comunidades siguen impregnadas de un espíritu de solidaridad y reciprocidad.

Por último, aunque las comunidades ya no reciben asistencia gubernamental para el mantenimiento de los sistemas de riego, cuentan desde hace varias décadas con instituciones para gestionar estos sistemas. De hecho, desde los años noventa, los comités de riego dependen de la participación monetaria o laboral para el mantenimiento de la infraestructura. De tal modo que el Instituto Nacional de Desarrollo Rural (Inder), la institución que debía tomar el relevo de Corpoandes, no asesoró a los comités de riego en la gestión de los sistemas de riego, que siguieron autogestionados. Por eso, a pesar de la gran crisis que afecta a la agricultura en los Andes venezolanos, estas asociaciones de regantes siguen gestionando los sistemas de riego.

Sin embargo, aunque el acceso al agua fue durante mucho tiempo esencial para el desarrollo de la agricultura intensiva, la drástica reducción de la demanda de productos de horticultura podría llevar a un abandono gradual de los sistemas de riego, en la medida que los agricultores no tendrán el capital necesario para mantener la infraestructura.

\section{CONCLUSIÓN}

Los Andes venezolanos, marginados durante mucho tiempo por las políticas extractivas del petróleo del Estado venezolano, se transformaron a partir de los años 1960 en centros de intensa actividad económica debido al desarrollo de la horticultura intensiva de regadío. Entre los factores que han favorecido la emergencia y la estructuración de estas áreas productivas, el desarrollo estatal de pequeños sistemas de riego ha sido esencial. En este caso, se puede decir que el petróleo fue «sembrado».

Aunque el papel del Estado fue fundamental para el éxito de estos nuevos sistemas de producción, la demanda urbana de productos hortícolas representó un impulso considerable, como lo demuestran las transformaciones similares en Colombia y Ecuador. Además, parece obvio que algunos productores extranjeros (en particular españoles e italianos) promovieron el aprendizaje en las comunidades rurales y tuvieron un efecto dominó significativo. La revolución de la horticultura de mercado se desarrolló, por tanto, en un contexto particularmente favorable (Tulet, 2002). 
Si bien los Andes venezolanos fueron durante mucho tiempo una de las áreas agrícolas más productivas de Venezuela, ahora están presentando las consecuencias de dos décadas de políticas económicas inconsistentes. La crisis económica, política y social pone de manifiesto los errores de una economía basada en los ingresos del petróleo que destruyó totalmente la agricultura del país. Hoy en día los agricultores venezolanos enfrentan una multitud de dificultades que hacen que la inversión agrícola sea particularmente arriesgada: escasez de combustible, dolarización de la economía, pérdida de poder adquisitivo de los consumidores, costos de mantenimiento de los vehículos, altos costos de los insumos, falta de financiamiento, entre otros factores. En tal sentido, la agricultura, como todos los sectores productivos en Venezuela, se enfrenta ahora a una crisis sin precedentes.

Aunque todas las zonas agrícolas del país fueron afectadas por este fenómeno, parece que las comunidades rurales andinas venezolanas tienen una buena capacidad de adaptación, en especial debido a una agricultura que todavía se basa en el trabajo familiar y que puede contar con relaciones de apoyo mutuo. Además, aunque los agricultores no han abandonado los cultivos comerciales, el retorno de la agricultura de subsistencia permite a los agricultores producir suficientes alimentos para ellos y sus familias. Todos estos elementos juntos explican por qué las zonas rurales de los Andes están menos afectadas por el éxodo de los venezolanos hacia los países vecinos que otras zonas del país.

Sin embargo, en un contexto de crisis alimentaria como el que presenta Venezuela, el retorno de la agricultura de subsistencia en los Andes podría en última instancia disminuir la seguridad alimentaria a nivel nacional, porque muchas verduras ya no llegarán a los mercados de las grandes ciudades. Por lo tanto, es esencial fortalecer la horticultura en esta región a través de políticas agrícolas orientadas hacia la producción local de productos alimentarios en cantidades suficientes para alimentar a la población venezolana.

\section{AGRADECIMIENTOS}

Quiero agradecer a los habitantes de los Andes venezolanos. Gracias a Efraín Porto Tapiquén por su ayuda en la elaboración del mapa, así como a Héctor Alfonso Martínez Castillo y Sara Barrasa García por la revisión de este manuscrito. Finalmente, quiero agradecer a los revisores anónimos, así como al consejo editorial de la revista Historia Agraria, por sus útiles sugerencias. 


\section{REFERENCIAS}

Aguilar, L. A. (1978). El subsidio conservacionista y la difusión y adopción de innovaciones tecnológicas. Tesis de maestría. Mérida: Universidad de los Andes.

Altieri, M. A. \& Toledo, V. M. (2011). The Agroecological Revolution in Latin America: Rescuing Nature, Ensuring Food Sovereignty and Empowering Peasants. Fournal of Peasant Studies, 38 (3), 587-612.

Alto Comisionado de las Naciones Unidas para los ReFugiados (ACNUR) (2019). Aspectos claves del monitoreo de protección: Situación Venezuela. Ginebra: ACNUR. https://www.acnur.org/5d321d124.pdf

Angéliaume-Descamps, A., Blot, F. \& Leroy, D. (2013). Dynamique récente des relations aux zones humides des páramos andins vénézuéliens: Entre fonctionnalisme et mystique. Géocarrefour, 88 (4), 285-298.

AngÉliaume-Descamps, A. \& Oballos, J. (2009). Le maraîchage intensif irrigué dans les hautes vallées andines vénézuéliennes: Quelle remise en question? Cahiers d'Outre-Mer, (247), 439-468.

AngÉliaume-Descamps, A. \& Tulet, J. C. (2009). Mutation maraîchère et accompagnement institutionnel dans les Andes du Venezuela (1950-2007). En O. CoMPAGNON, J. Rebotier \& S. Revet (Eds.), Le Venezuela au-delà du mythe: Chavez, la démocratie, le changement social (pp. 185-199). Paris: Atelier.

BANCO CENTRAL DE VENEZUELA (BCV) (2019). Información estadística: Exportaciones y PIB. http://www.bcv.org.ve

BERGQUIST, C. W. (1988). Los trabajadores en la historia latinoamericana: Estudios comparativos de Chile, Argentina, Venezuela y Colombia. México, DF: Siglo XXI.

CoRPOANDES (2004) Inventario de pequeños sistemas de riego del Estado Mérida. Mérida: MAT-Corpoandes.

EnríqueZ, L. J. \& Newman, S. J. (2016). The Conflicted State and Agrarian Transformation in Pink Tide Venezuela. Fournal of Agrarian Change, 16 (4), 594-626.

Fardmanesh, M. (1991). Dutch Disease Economics and Oil Syndrome: An Empirical Study. World Development, 19 (6), 711-717.

Food and Agricultural Organization of United Nations-Statistical Database [FAOSTAT] (2017). Cultivos. http://www.fao.org/faostat/es/\#data/QC/visualize.

FEDEAGRO (2019). Estadísticas agrícolas. https://fedeagro.org/estadisticas-agricolas/

FEDEAGRO (2020). La catástrofe agrícola del año 2019. https://fedeagro.org/resultadosde-la-agricultura-vegetal-del-2018/

FonSECA SÁNCHEZ, J. C. \& GuTIÉRREZ, A. (2017). Agricultura por contrato: Impactos económicos e institucionales en el municipio Rangel del estado Mérida, Venezuela. Cuadernos del CENDES, 34 (94), 031-048. 
GONZÁLEZ CORTÉs, W. R. (2016). La reforma agraria en Venezuela durante el gobierno de Hugo Rafael Chávez Frías: Ideas y realidades. Tesis de maestría. Bogotá: Universidad Nacional de Colombia.

GuTIÉRREZ, A. (1998). Globalización, ajustes estructurales y agricultura: La experiencia de Venezuela. Cuadernos de Desarrollo Rural, (41), 21-46.

HERNÁNDEZ, L. E. (2006). La renta petrolera y su impacto en el crecimiento económico de Venezuela. Problemas del desarrollo, 37 (145), 135-151.

Hofstede, R., Segarra, P. \& Mena, P. (Eds.) (2003). Los páramos del mundo: Proyecto Atlas Mundial de los Páramos. Quito: UICN/Global Peatland Initiative/Ecociencia. IsmaIl, K. (2010). The Structural Manifestation of the 'Dutch Disease': The Case of Oil Exporting Countries. Washington, DC: International Monetary Fund.

Kappeler, A. (2013). Perils of Peasant Populism: Why Redistributive Land Reform and "Food Sovereignty" Can't Feed Venezuela. Documento presentado en la conferencia internacional "Food Sovereignty: A Critical Dialogue". Yale, 14-15 de septiembre.

LAVELle, D. (2013). A Twenty First Century Socialist Agriculture?: Land Reform, Food Sovereignty and Peasant-State Dynamics in Venezuela. International fournal of Sociology of Agriculture and Food, 21 (1), 133-154.

Leroy, D. (2017). Les vulnérabilités liées à l'eau dans les páramos colombiens et vénézuéliens. Tesis de doctorado. Toulouse: Université Toulouse II-Jean Jaurès.

Leroy, D. (2019). Farmers' Perceptions of and Adaptations to Water Scarcity in Colombian and Venezuelan Páramos in the Context of Climate Change. Mountain Research and Development, 39 (2).

Leroy, D., Angéliaume-Descamps, A., Antoine, J., Blot, F., Maire, E. \& Peltier, A. (2013). Représentations et pratiques autour de la ressource en eau des producteurs maraîchers des Andes vénézuéliennes. [VertigO]: La revue électronique en sciences de l'environnement, 13 (1).

LLAMBí, L. \& ARIAS, E. (1997). Impactos de las políticas de ajuste estructural en los productores paperos y hortícolas de los Andes venezolanos: El caso de Pueblo Llano, estado Mérida. Agroalimentaria, 3 (4), 3.

Llambí, L. \& Cousins, A. L. (1989). Petty-Capitalist Production in Agriculture: Lessons from Five Case Studies in Venezuela, 1945-1983. Latin American Perspectives, 16 (3), 86-120.

Llambí, L. D. \& RADA, F. (2019). Ecological Research in the Tropical Alpine Ecosystems of the Venezuelan Páramo: Past, Present and Future. Plant Ecology \& Diversity, (12) $11,1-20$.

Llambí, L. D., Smith, J. K., Pereira, N., Pereira, A. C., Valero, F., Monasterio, M. \& DÁvila, M.V. (2005). Participatory Planning for Biodiversity Conservation in the High Tropical Andes: Are Farmers Interested? Mountain Research and Development, 25 (3), 200-205. 
LeZAMA, P.V. (2019). Les distorsions des politiques d'alimentation de la «révolution bolivarienne». Revue internationale des études du développement, (1), 191-210.

López MAYA, M. \& LANDER, L. E. (1999). Triunfos en tiempos de transición: Actores de vocación popular en las elecciones venezolanas de 1998. Estudios Latinoamericanos, 7 (12-13), 283-302.

LubBock, R. (2020). The Hidden Edifice of (Food) Sovereignty: Rights, Territory, and the Struggle for Agrarian Reform in Venezuela. Fournal of Agrarian Change, 20 (2), 289-310.

McKay, B., Nehring, R. \& Walsh-Dilley, M. (2014). The 'State'of Food Sovereignty in Latin America: Political Projects and Alternative Pathways in Venezuela, Ecuador and Bolivia. Fournal of Peasant Studies, 41 (6), 1175-1200.

Monasterio, M. \& Molinillo, M. (2003). Venezuela: El paisaje y su diversidad. En R. Hofstede, P. Segarra \& P. Mena (Eds.), Los páramos del mundo: Proyecto Atlas Mundial de los Páramos (pp. 205-236.). Quito: UICN/Global Peatland Initiative/Ecociencia.

MORALES, A. (1985). Una interpretación del problema agrícola venezolano a partir del estudio de la integración de su industria alimentaria al Sistema Agroalimentario Internacional. Maracay: Universidad Central de Venezuela.

Morales, A. (2002). El sector agrícola y el abastecimiento alimentario en los países exportadores de petróleo: el caso venezolano. Revista Venezolana de Economía y Ciencias Sociales, 8 (2), 103-128.

Morales, A. (2009). La cuestión agroalimentaria en Venezuela. Nueva Sociedad, 223, 128-46.

Ministerio del Poder Popular para la Agricultura y Tierras (MPPAT) (19972015). Memoria y Cuenta de 1997 a 2015. Caracas: República Bolivariana de Venezuela.

Organización de Países Exportadores de Petróleo (OPEC) (2018). OPEC monthly oil market report. Viena: OPEC. www.opec.org/opec_web/en/publications/338.htm

Orhangazi, Ö. (2014). Contours of Alternative Policy Making in Venezuela. Review of Radical Political Economics, 46 (2), 221-240.

PARKER, D. (2008). Chávez y la búsqueda de una seguridad y soberanía alimentarias. Revista Venezolana de Economía y Ciencias Sociales, 14 (3), 121-143.

PINTo, G. (1966). Agricultura y desarrollo: El caso venezolano. Caracas: Centro de Estudios del Desarrollo/Universidad Central de Venezuela.

Puente, J. M. \& Simont, J. (2018). Histoire d'un désastre économique et social. Les Temps Modernes, (697), 197-209.

Purcell, T. F. (2013). The Political Economy of Social Production Companies in Venezuela. Latin American Perspectives, 40 (3),146-168. 
Purcell, T. F. (2017). The Political Economy of Rentier Capitalism and the Limits to Agrarian Transformation in Venezuela. Fournal of Agrarian Change, 17 (2), 296-312. República Bolivariana deVenezuela (1999). Constitución de la República Bolivariana de Venezuela. Gaceta Oficial Extraordinaria, n. ${ }^{\circ} 36.860$ de fecha 30 de diciembre.

República Bolivariana de Venezuela (2008). Ley Orgánica de Seguridad y Soberanía Agroalimentaria. Gaceta Oficial, n. ${ }^{\circ} 5.981$ de fecha 31 de julio.

Richer, M. (2005). Innovación social y desarrollo local en un municipio andino. Cayapa. Revista Venezolana de Economía Social, 5 (9), 50-64.

RoBERT, P. DE (1991). Immigration et transformation dans les Andes du café: Le cas de Mucunután. Geodoc, (36), 44-60.

Romero, L. \& Monasterio, M. (2005). Semilla, actores e incertidumbres en la producción papera de Los Andes de Mérida. Revista Venezolana de Economía Social, 5 (9), 35-58

Romero, L. \& Romero, R. (2007). Agroecología en los Andes venezolanos. Investigación, (15), 52-57.

SChIAVONI, C. M. (2015). Competing Sovereignties, Contested Processes: Insights from the Venezuelan Food Sovereignty Experiment. Globalizations, 12 (4), 466-480.

Schiavoni, C. M. (2017). The Contested Terrain of Food Sovereignty Construction:Toward a Historical, Relational and Interactive Approach. The fournal of Peasant Studies, 44 (1), 1-32.

Smith, J. K. \& Romero, L. (2012). Factores condicionantes de la dinámica espacial de la agricultura en los Andes venezolanos y sus consecuencias sobre el ecosistema páramo. Informe final de proyecto. Mérida: Universidad de Los Andes.

Smith, J. K., Sarmiento, L., Acevedo, D. \& Dimas, R. (2007). Mapeo de fincas y recolección de información agrícola a través de investigación participativa. Informe final. Fundacite. Mérida: Universidad de Los Andes.

SuÁREZ, M. M. (1979). Migrations, travail agricole et dissolution de la réciprocité dans les Andes vénézuéliennes. Études rurales, 75 (1), 105-111.

Tulet, J. C. (1987). Evaluación cualitativa del impacto de los sistemas de riego en los valles altos de los Andes venezolanos. Mérida: Corpoandes.

Tulet, J. C. (1999). El fuerte crecimiento del número de explotaciones agrícolas en Venezuela. Revista agroalimentaria, 5 (9), 15-20.

Tulet, J. C. (2002). La révolution du maraîchage dans les Andes du Venezuela. Cahiers d'Amérique latine, (40), 49-64

Universidad Central de Venezuela, Universidad Católica Andrés Bello \& UniVERSIDAd Simón Bolivar (2018). Encuesta Nacional de Condiciones deVida (Encovi): Avances de Resultados. http://elucabista.com/wp-content/uploads/2018/11/RESULTADOS-PRELIMINARES-ENCOVI-2018-30-nov.pdf 
Uslar Pietri, A. (2005). Sembrar el petróleo. Revista de Artes y Humanidades UNICA, 6 (12), 231-233.

VELÁzQUEZ, N. (2001a). Dinámica socioambiental y modernización agrícola en los valles altos andinos: Mucuchies y Timotes (1930-1999). Tesis de doctorado. Mérida: ICAE/Universidad de Los Andes.

VELÁZQUEZ, N. (2001b). Inmigrantes, cambios tecnológicos y diversificación agrícola en los Andes Venezolanos. Agroalimentaria, 7 (13), 85-98.

VerA, L. (2018). Cómo explicar la catástrofe económica venezolana. Nueva Sociedad, (274), 83-96. 
